\title{
Trends in vital signs and routine biomarkers in sepsis patients during resuscitation in the emergency department: a prospective observational pilot study
}

\author{
VM Quinten ${ }^{1 *}$, M Van Meurs $^{2,3}, J C$ Ter Maaten ${ }^{1}$, JJM Ligtenberg $^{1}$ \\ From ESICM LIVES 2015 \\ Berlin, Germany. 3-7 October 2015
}

\section{Introduction}

Sepsis lacks a reliable measure of disease activity $[1,2]$. Therefore, it remains unclear how to monitor the response to treatment. Little is known about changes in vital signs during sepsis resuscitation and biomarkers for disease activity are not available to evaluate effects of treatment in sepsis patients at the bedside [2,3]. Trends in vital signs and biomarker levels during resuscitation might provide information about response to treatment at a very early stage of sepsis.

\section{Objectives}

Detect trends in vital signs and routine biomarker levels during sepsis resuscitation in the emergency department (ED).

\section{Methods}

Prospective observational pilot study in the ED of a tertiary care teaching hospital. Adult non-trauma patients with two or more SIRS criteria and suspected infection were included. Blood samples were taken and vital signs (heart rate, blood pressure, respiratory rate, oxygen saturation and temperature) measured at admittance to the $\mathrm{ED}\left(\mathrm{T}_{0}\right)$ and 3 hours later $\left(\mathrm{T}_{1}\right)$ and the differences between $\mathrm{T} 0$ and $\mathrm{T} 3$ (delta) were analyzed.

\section{Results}

In total data of 99 patients was analyzed. Of these patients, 63 presented with sepsis, 30 with severe sepsis and 6 patients had septic shock. Trends in vital signs

\footnotetext{
'University Medical Center Groningen, Emergency Department, Groningen, Netherlands

Full list of author information is available at the end of the article
}

and routine biomarker levels are respectively shown in Figure 1 and Figure 2. All vital signs decreased, except for peripheral oxygen saturation which increased. The heart rate and respiratory rate dropped by over $10 \%$ during resuscitation $(\mathrm{p}<0.001)$. At the same time, the systolic and diastolic blood pressure decreased respectively with $5 \%$ and more than $9 \%(\mathrm{p}<0.001)$. Almost all biomarker levels decreased during resuscitation, except for CRP, bands, potassium, Troponin $\mathrm{T}$ and direct

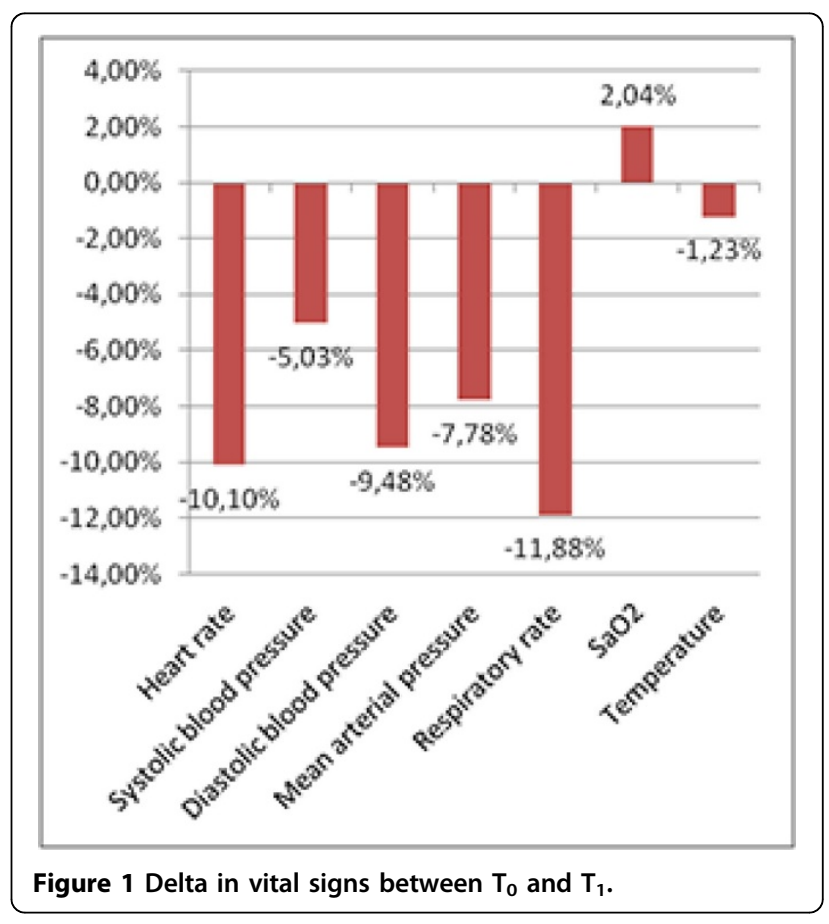

C 2015 Quinten et al.; This is an Open Access article distributed under the terms of the Creative Commons Attribution License (http:// creativecommons.org/licenses/by/4.0), which permits unrestricted use, distribution, and reproduction in any medium, provided the original work is properly cited. 


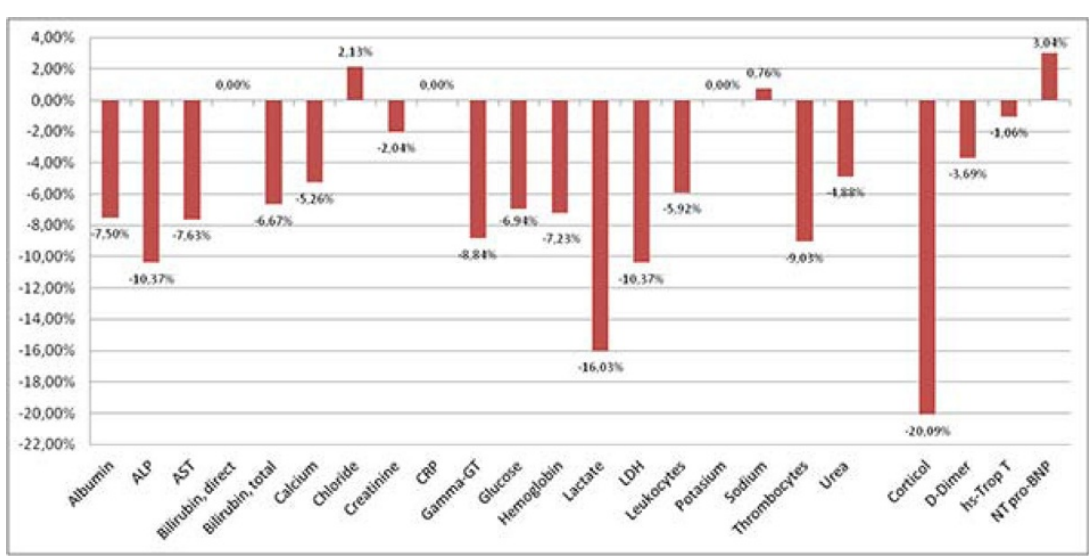

Figure 2 Delta in biomarker levels between $T_{0}$ and $T_{1}$.

bilirubin that remained stable. Sodium, chloride and NT pro-BNP increased slightly.

\section{Conclusions}

Vital signs and biomarker levels showed descending trends during resuscitation, except for parameters directly affected by treatment modalities. Despite these trends patients clinically improved. Trends in vital signs and routine biomarkers might be helpful in predicting clinical course and response to treatment in sepsis patients.

\section{Authors' details}

'University Medical Center Groningen, Emergency Department, Groningen, Netherlands. ${ }^{2}$ University Medical Center Groningen, Department of Critical Care, Groningen, Netherlands. ${ }^{3}$ University Medical Center Groningen, Department of Pathology and Medical Biology, Medical Biology Section, Groningen, Netherlands.

Published: 1 October 2015

\section{References}

1. Marshall JC, Vincent J, Guyatt G, Angus DC, Abraham E, Bernard G, Bombardier C, Calandra T, Jørgensen HS, Sylvester R: Outcome measures for clinical research in sepsis: a report of the 2nd Cambridge Colloquium of the International Sepsis Forum. Crit Care Med 2005, 33:1708-1716.

2. Dellinger RP, Levy MM, Rhodes A, Annane D, Gerlach H, Opal SM, Sevransky JE, Sprung CL, Douglas IS, Jaeschke R: Surviving Sepsis Campaign: international guidelines for management of severe sepsis and septic shock, 2012. Intensive Care Med 2013, 39:165-228.

3. Samraj RS, Zingarelli B, Wong HR: Role of biomarkers in sepsis care. Shock 2013, 40:358-365.

doi:10.1186/2197-425X-3-S1-A301

Cite this article as: Quinten et al:: Trends in vital signs and routine biomarkers in sepsis patients during resuscitation in the emergency department: a prospective observational pilot study. Intensive Care Medicine Experimental 2015 3(Suppl 1):A301.

\section{Submit your manuscript to a SpringerOpen ${ }^{\circ}$ journal and benefit from:}

- Convenient online submission

- Rigorous peer review

- Immediate publication on acceptance

- Open access: articles freely available online

- High visibility within the field

- Retaining the copyright to your article

Submit your next manuscript at $>$ springeropen.com 